\title{
MICROENVIRONMENTAL EFFECT ON CHARGE TRANSFER FLUORESCENCE IN ION-PAIR CT COMPLEXES OF 4,4'-BIPYRIDINIUM SALT
}

\author{
YUJI ISODA ${ }^{*}$ and TOSHIHIKO NAGAMURA*,** \\ *Department of Electronic Materials Science, Graduate School of Electronic Science and \\ Technology \\ **Crystalline Films Laboratory, Research Institute of Electronics, \\ Shizuoka University, 3-5-1 Johoku, Hamamatsu 432, Japan
}

Temperature dependence of charge transfer (CT) fluorescence were studied by time-resolved spectroscopies in thin polymer films containing 4,4'-bipyridinium tetrakis [3,5-bis(trifluoromethyl)phenyl]borate salts as part of the main chain at $10-300^{\circ} \mathrm{K}$. The time-resolved fluorescence with peaks at $432 \mathrm{~nm}$ and $500 \mathrm{~nm}$ appeared upon excitation of ion-pair chargetransfer absorption at room temperature at about 360 and $390 \mathrm{~nm}$, respectively. A shorter wavelength peak shifted from $432 \mathrm{~nm}$ to $402 \mathrm{~nm}$ with decreasing temperature from $300^{\circ} \mathrm{K}$ to $10^{\circ} \mathrm{K}$. The fluorescence decay curve was analyzed by a fast $(\tau=3-6 \mathrm{~ns})$ and a slow $(\tau=15 \mathrm{~ns})$ component. The former corresponded to a shorter wavelength peak and the latter to that at ca. $500 \mathrm{~nm}$ for CT fluorescence spectra of 4,4'-bipyridinium salt. A reaction mechanism is proposed based on these results.

\section{Introduction}

Various photochromic systems employing polymeric thin films or Langmuir-Blodgett (LB) films have recently attracted much interest in view of their promising applicability to high-speed and high-density photon-mode optical memory. The photochromism reported so far involves changes of chemical bonds such as heterolytic cleavage of a pyran ring in spiropyrans or cis-trans isomerization in azobenzenes.[1]

Recently we have reported novel photochromism (photoinduced electrochromism) in organic solutions[2,3], microcrystals[4,5], LB films[6-11], and polymer films[11-15], which was due only to the photoinduced electron transfer reaction via the excited state of specific ion-pair charge-transfer (IPCT) complexes[16,17] of 4,4'-bipyridinium salts with tetrakis[3,5-bis(trifluoromethyl)phenyl]borate[18] (abbreviated to TFPB ${ }^{-}$). The photochemical colouring and the thermal fading due to the reverse electron transfer were highly reversible in deaerated atmosphere in all systems[2- 
15]. The lifetime of coloured (blue) state depended markedly on the microenvironments and temperatures.

4,4'-Bipyridinium TFPB- salts are known to show broad structureless with a maximum at $525 \mathrm{~nm}$ fluorescence from excited IPCT state in 1,2-dimethoxyethane solutions at room temperature[16]. The excitation of a CT band $\left(\lambda_{\mathrm{ex}}=475 \mathrm{~nm}\right)$ in an oxygen-free atmosphere resulted in the quenching of $C T$ fluorescence accompanied by a remarkable colour change from pale yellow to blue owing to the accumulation of 4,4'-bipyridinium radical cations. After disappearance of blue colour in about an hour at $20^{\circ} \mathrm{C}$, the CT absorbance and fluorescence intensity in DME recovered very gradually to the equilibrium values. The CT fluorescence and colour changes were repeated reversibly. These results demonstrated that 4,4'-bipyridinium TFPB- salts can be applied to a photon-mode-type optical memory which can be read with either absorption or emission[19]. The observed ps fluorescence decay behavior did not correspond with the formation rate of transient absorption at about $600 \mathrm{~nm}$ which was much faster than the fluorescence decay. The ps timeresolved fluorescence spectra in 4,4'-bipyridinium polymer films have a broad and slow-decaying component with a peak at $490 \mathrm{~nm}$ and a less broad short-lived one with a peak at about $440 \mathrm{~nm}$ at room temperature[20]. In the present paper microenvironmental effects on charge transfer fluorescence in IPCT complexes of 4,4'-bipyridinium salts with TFPB- in polymer films are discussed.

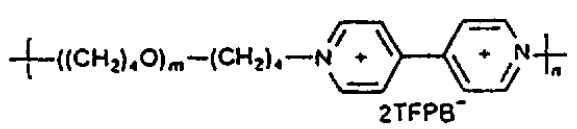

\section{Experimental}

\section{Materials}

The structure of a polymer containing 4,4'bipyridinium tetrakis[3,5-bis(trifluoromethyl)phenyl]borate (TFPB-) as part of the main chain is shown in Fig. 1. The content of 4,4-bipyridinium ions is $2.3 \mathrm{x}$ $10^{-4} \mathrm{~mol} / \mathrm{g}$. Transparent and uniform films were obtained by casting 1,2-dimethoxyethane solution of this polymer onto a glass plate.

\section{Measurement}

Polymer films were thoroughly degassed in a cryostat with Iwatani Plantech ultra-low-temperature cooling units. The fluorescence decay curve and the time-resolved fluorescence spectrum were measured on Horiba NAES-700F with a N2 ns lamp NFL-700 in vacuo at controlled temperature. For time-resolved

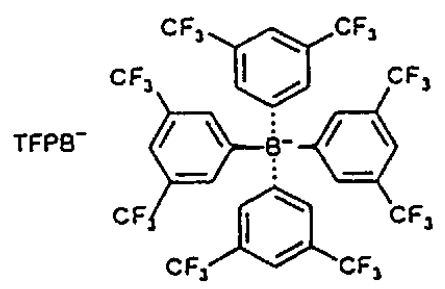

Fig. 1 The structure of the elastic polymer $\mathrm{PV}^{2+}\left(\mathrm{TFPB}^{-}\right)_{2}$ containing bipyridinium ions and tetrakis[3,5-bis(trifluoromethyl)phenyl]borate anion

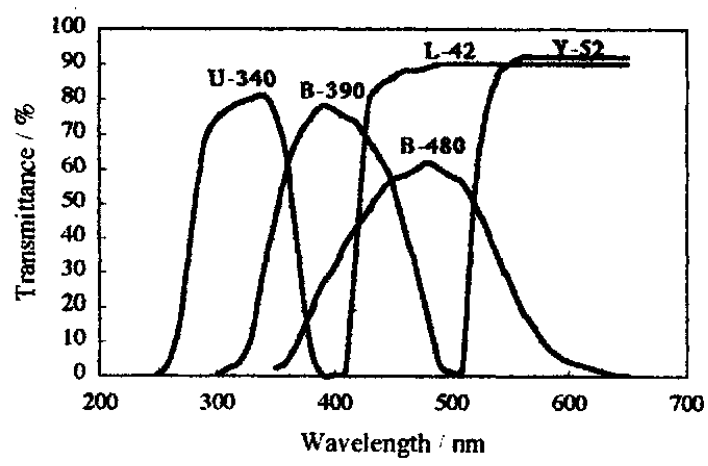

Fig. 2 The transparent spectra of the band-pass and sharp-cut filters used in the present experiment. 
emission spectrum measurements either U-340 and B-390 band-pass filters for 400-432 nm emission or B-390 band-pass filter for $500 \mathrm{~nm}$ emission were used to excite their CT absorption band alone. For time-resolved excitation spectrum either B-390 and L-42 filters or B-480 and Y-52 filters were used to monitor CT fluorescence at $400-432 \mathrm{~nm}$ as shown in Fig. 2.

The DSC thermogram was recorded by a MAC Science DSC 3100 Thermal Analysis Station from $150^{\circ} \mathrm{K}$ to $340^{\circ} \mathrm{K}$ with a heating rate of $5^{\circ} \mathrm{K} / \mathrm{min}$.

\section{Results}

Fig. 3 shows the time-resolved fluorescence spectra of the polymer film excited at $350-400$ $\mathrm{nm}$ at various temperatures. Fluorescence spectra were observed with a peak around $400-432 \mathrm{~nm}$.
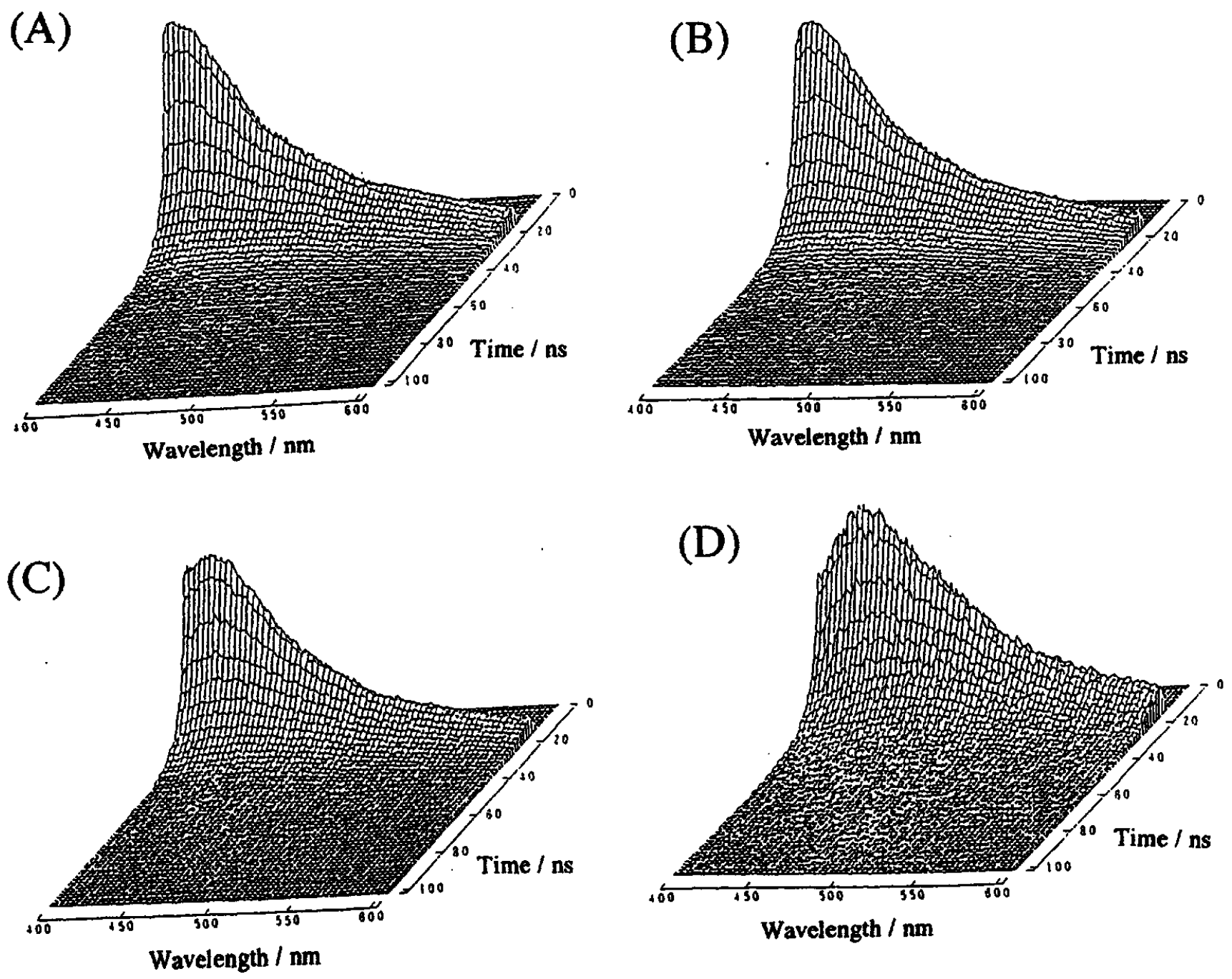

Fig. 3 The time-resolved fluorescence spectra of $\mathrm{PV}^{2+}\left(\mathrm{TPPB}^{-}\right)_{2}$ excited at $350-400 \mathrm{~nm}$ at (A) $10^{\circ} \mathrm{K}$, (B) $100^{\circ} \mathrm{K}$, (C) $200^{\circ} \mathrm{K}$ and (D) $300^{\circ} \mathrm{K}$ 


\section{J. Photopolym. Sci. Technol., Vol.8, No.1, 1995}

Another fluorescence peak at about $500 \mathrm{~nm}$ was observed upon excitation at $460 \mathrm{~nm}$ as shown in Fig. 4. The fluorescence band at 400-432 nm showed faster decay and shifted to longer wavelength with increasing temperature from 200 ${ }^{\circ} \mathrm{K}$ to $300{ }^{\circ} \mathrm{K}$, whereas no temperature dependence was observed below $100^{\circ} \mathrm{K}$. The fluorescence band with a faster decay was broadened with increasing temperature as shown in Fig. 3. The fluorescence band at $500 \mathrm{~nm}$ showed slower decay and became predominant

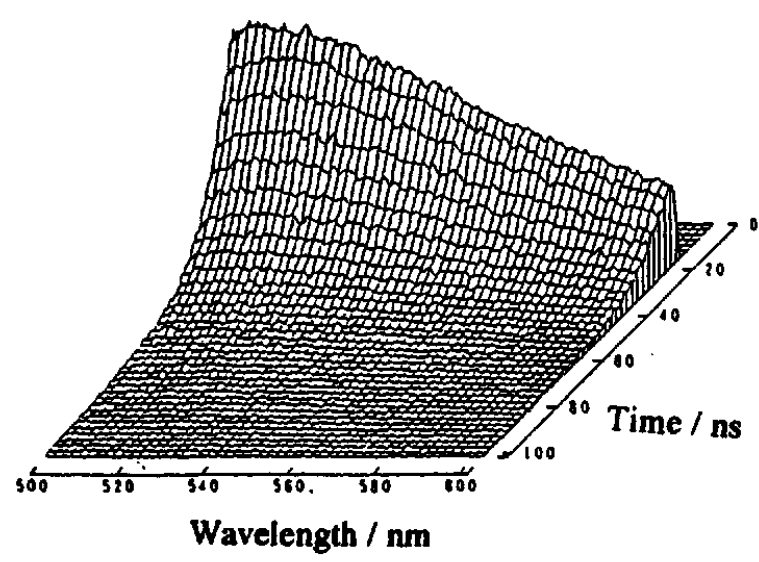

Fig. 4 The time-resolved fluorescence spectra of $\mathrm{PV}^{2+}\left(\mathrm{TFPB}^{-}\right)_{2}$ excited at $460 \mathrm{~nm}$ at room temperature. with increasing temperature.

Fig. 5 shows the time-resolved fluorescence excitation spectra of $\mathrm{PV}^{2+}\left(\mathrm{TFPB}^{-}\right)_{2}$ at room temperature. The fluorescence excitation spectrum corresponded with the charge-transfer absorption spectrum except the shorter wavelength region than about $380 \mathrm{~nm}$, where the fluorescence quantum yield was very low due to dissociation. The profile of fluorescence excitation spectra did not depend upon temperature. The fluorescence excitation spectrum monitored at 420 $\mathrm{nm}$ showed peaks at $350 \mathrm{~nm}, 375 \mathrm{~nm}, 400 \mathrm{~nm}$ as shown in Fig. $5(A)$. The fluorescence excitation spectrum monitored at $500 \mathrm{~nm}$ showed an additional peak around $460 \mathrm{~nm}$ as shown in Fig. 5(B). For the emission band at $500 \mathrm{~nm}$ the time resolved fluorescence excitation spectra showed a "rise" as shown in Fig. 5(D).

Fig. 6 shows the fluorescence decay curves of $\mathrm{PV}^{2}+\left(\mathrm{TFPB}^{-}\right)_{2}$ at room temperature at (A) $420 \mathrm{~nm}$ and (B) $500 \mathrm{~nm}$. The fluorescence decay curves were fitted with triple-exponential with lifetimes of $3 \mathrm{~ns}, 6 \mathrm{~ns}$ and 10-30 ns. The fluorescence band at a shorter wavelength had faster decay and the longer band had slower.

Fig. 7 shows the fluorescence lifetime versus temperature between $10^{\circ} \mathrm{K}$ and $300{ }^{\circ} \mathrm{K}$. A fastest component at $400 \mathrm{~nm}$ emission was independent of temperature. The second one depended on temperatures and showed a considerable change at $175^{\circ} \mathrm{K}$ and $275^{\circ} \mathrm{K}$. Such temperatures corresponded to the glass transition temperature and the melting temperature of microcrystals of tetrahydrofuran units as shown in Fig. 8 [13]. The slow component decreased gradually above 150 ${ }^{\circ} \mathrm{K}$ as shown in Fig. 7.

Fig. 8 shows the DSC thermogram of $\mathrm{PV}^{2+}\left(\mathrm{TFPB}^{-}\right) 2$ from $150^{\circ} \mathrm{K}$ to $340^{\circ} \mathrm{K}$. The transition temperatures were observed at 165,255 and $290{ }^{\circ} \mathrm{K}$ corresponding to the glassy transition temperature, the crystallization temperature and the melting temperature of microcrystals of tetrahydrofuran units respectively. 

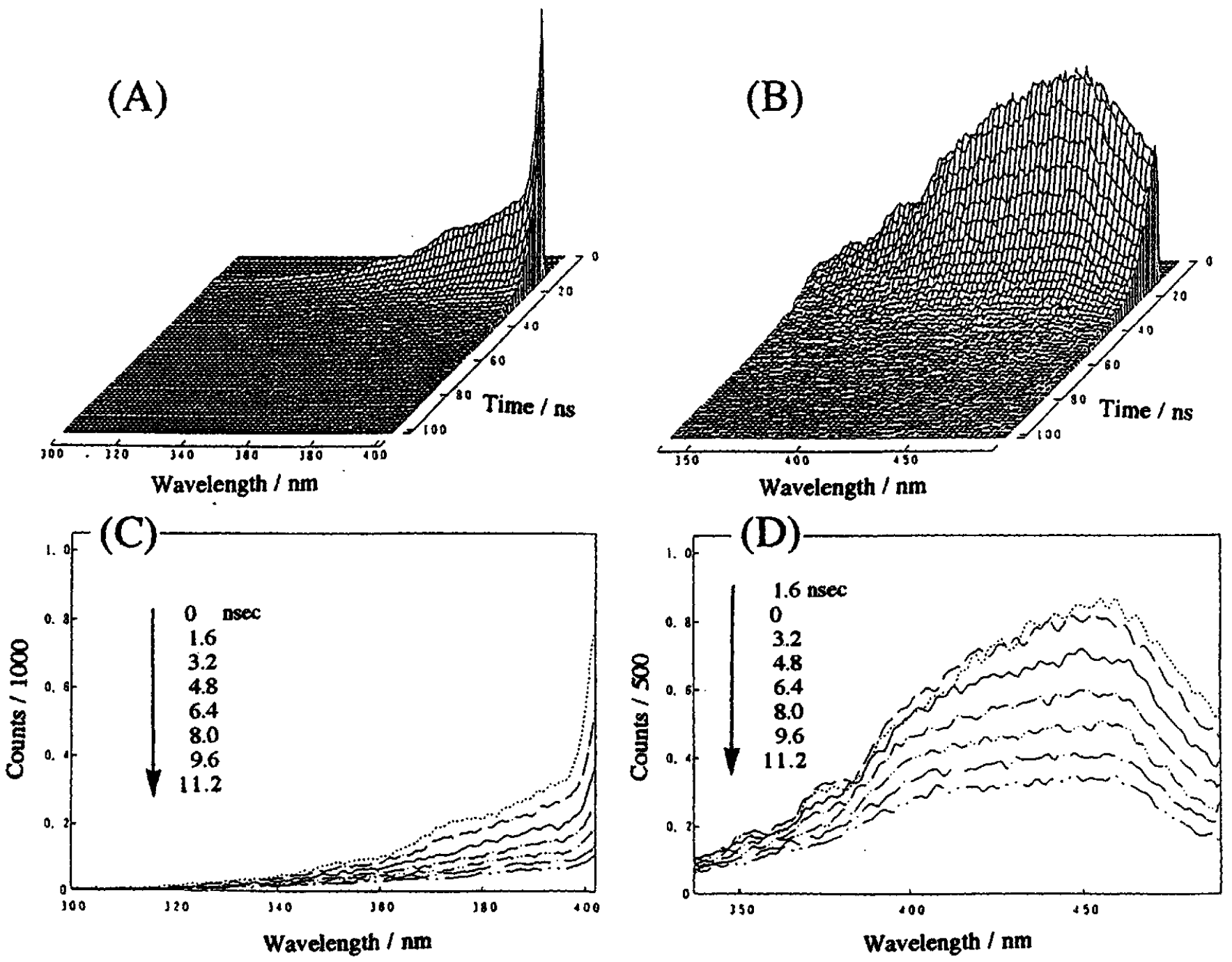

Fig. 5 The time-resolved fluorescence excitation spectra of $\mathrm{PV}^{2+}\left(\mathrm{TFPB}^{-}\right) 2$ at room temperature monitored at (A), (C) $420 \mathrm{~nm}(A),(C)$ and $500 \mathrm{~nm}(B),(D)$ emission. The time in (C) and (D) is the delay from the excitation pulse.

(A)
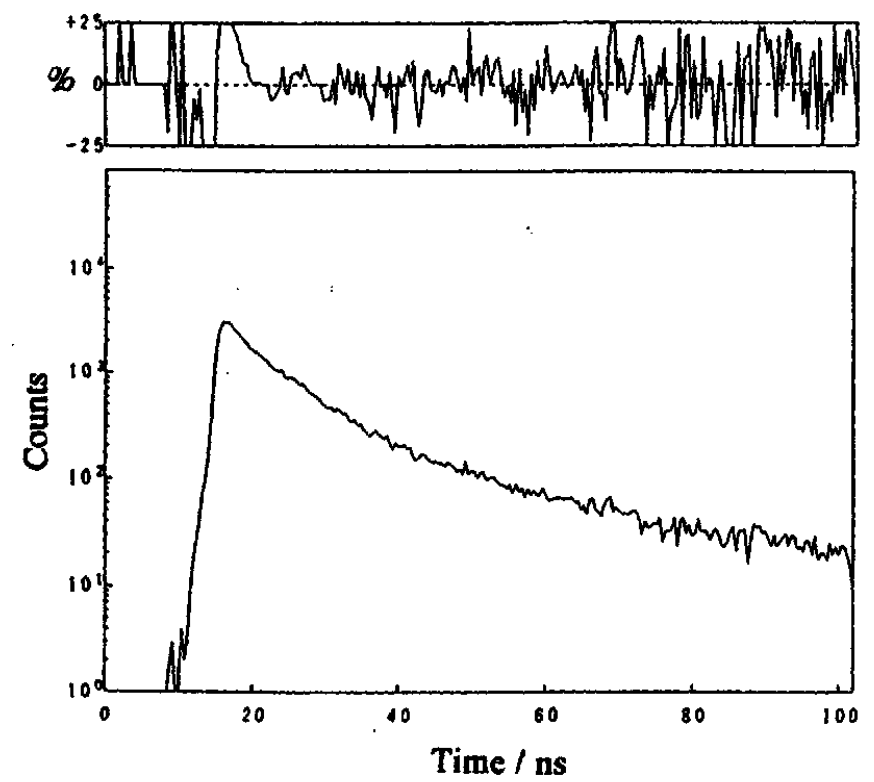

(B)
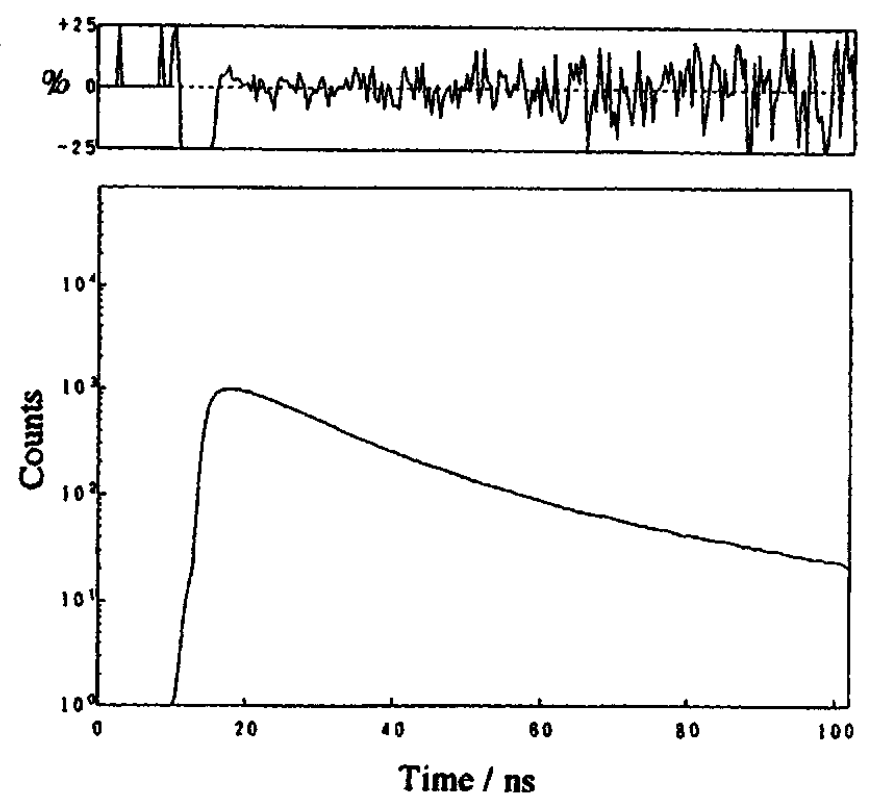

Fig. 6 The fluorescence decay curves of $\mathrm{PV}^{2+}\left(\mathrm{TFPB}^{-}\right) 2$ at room temperature at (A) $420 \mathrm{~nm}$ and (B) $500 \mathrm{~nm}$. 


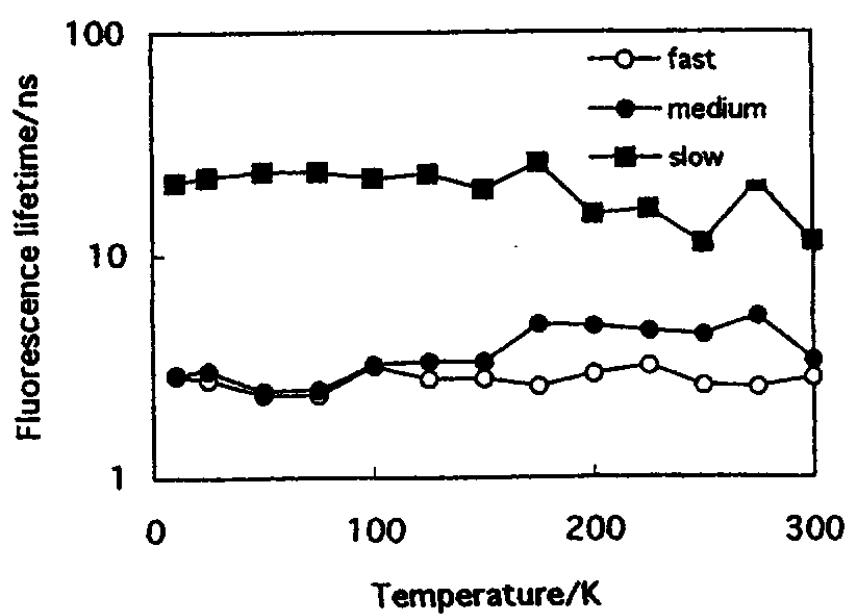

Fig. 7 The fluorescence lifetime versus temperature of $\mathrm{PV}^{2+}\left(\mathrm{TFPB}^{-}\right) 2$ excited at $350-400 \mathrm{~nm}$.

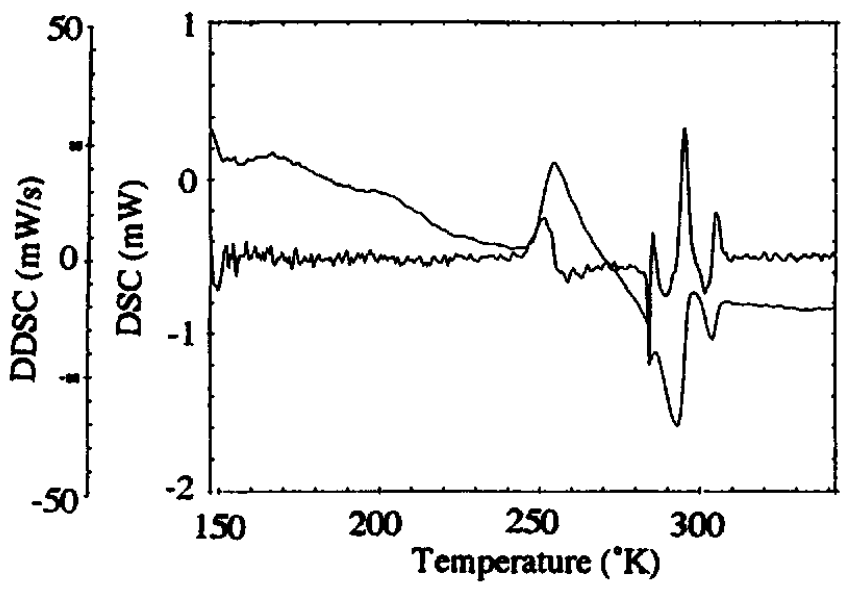

Fig. 8 The DSC thermogram of $\mathrm{PV}^{2+}\left(\mathrm{TFPB}^{-}\right)_{2}$ used in the present experiment.

\section{Discussion}

First, the peak shift of the shorter wavelength fluorescence showing a faster decay with temperatures will be considered. Such a peak shift might be caused by microenvironmental polarity changes below and above glass transition temperature $\left(T_{g}\right)$. The fluorescence excitation spectra showed no temperature dependence. The fluorescence excitation spectra of IPCT complexes of 4,4'-bipyridinium TFPB- salts have been reported to correspond with the IPCT absorption spectra except at the shorter wavelength region below about $400 \mathrm{~nm}$ [16]. If the fluorescence peak shift was caused by the microenvironmental polarity changes, the fluorescence excitation spectrum should show similar changes. These results excluded the possibility of microenvironmental polarity changes.

The fluorescence spectra with a faster decay were then assumed to consist of two fluorescence bands having peaks at $400 \mathrm{~nm}$ and $432 \mathrm{~nm}$. With increasing temperature above $\mathrm{T}_{\mathrm{g}}$, the fluorescence band became more broadened in addition to the peak shift from 402 to $432 \mathrm{~nm}$ as shown in Fig. 3. The cooling experiment from room temperature to $10^{\circ} \mathrm{K}$ gave a spectral shift from 432 to $402 \mathrm{~nm}$ and the sharpening of the fluorescence spectra.

The time-resolved IPCT fluorescence spectra and their temperature dependence in this $\mathrm{PV}^{2+}\left(\mathrm{TFPB}^{-}\right) 2$ system can be explained by potential surfaces as shown in Fig. 9. The ground state will be represented by two potential curves for $\left(\mathrm{D}^{-} \mathrm{A}^{+}\right)_{s}$ and $\left(\mathrm{D}^{-} \mathrm{A}^{+}\right) l$ corresponding to the different configuration of IPCT complexes. The subscript $s$ or 1 stands for shorter or longer wavelength fluorescence, respectively. $\left(\mathrm{D}^{-} \mathrm{A}^{+}\right)_{s}$ excited at $350-400 \mathrm{~nm}$ will become $\left(\mathrm{D}^{-} \mathrm{A}^{+}\right)_{s}{ }^{*}$. The potential surface of $\left(\mathrm{D}^{-} \mathrm{A}^{+}\right)_{s}{ }^{*}$ is assumed to have two local minima as shown in Fig. 9. The fluorescence from the upper local minimum will have a peak at $402 \mathrm{~nm}$. If the potential barrier of $\left(D^{+} A^{-}\right)_{S}{ }^{*}$ will be crossed over thermally at higher temperatures than $T_{g}$, the fluorescence at $432 \mathrm{~nm}$ will also be observed. The glass transition temperature and the melting temperature $\left(T_{\mathbf{m}}\right)$ affected 
the fluorescence lifetime as shown in Fig. 7. A second component with the intermediate lifetime appeared above $\mathrm{Tg}$ as shown in Fig. 7.

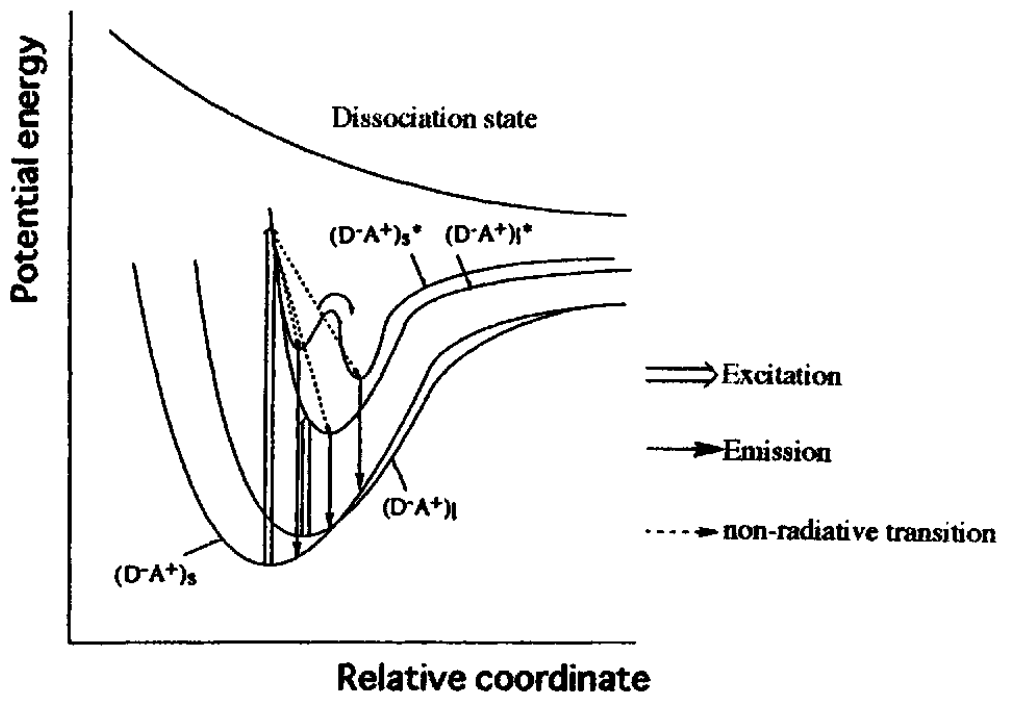

Fig. 9 Proposed potential surfaces for IPCT complexes of $\mathrm{PV}^{2+}\left(\mathrm{TFPB}^{-}\right)_{2}$.

The longer wavelength fluorescence with a peak at $500 \mathrm{~nm}$ was observed at all temperatures and excitation wavelength. $\left(\mathrm{D}^{-} \mathrm{A}^{+}\right) l$ will be excited either directly by longer wavelength excitation as shown in Fig.4 or by the energy transfer from $\left(\mathrm{D}^{-} \mathrm{A}^{+}\right)_{S}{ }^{*}$ formed upon shorter wavelength excitation. The fluorescence from $\left(\mathrm{D}^{-} \mathrm{A}^{+}\right) l^{*}$ will have a peak around $500 \mathrm{~nm}$ and a slower decay. The time-resolved fluorescence excitation spectra monitored at $500 \mathrm{~nm}$ showed the "rise" as shown in Fig. 5(D) strongly suggesting the energy transfer from $\left(\mathrm{D}^{-} \mathrm{A}^{+}\right)_{s}$. The fluorescence lifetime of the third component at $500 \mathrm{~nm}$ decreased around $\mathrm{Tg}$ and $\mathrm{Tm}$ as shown in Fig.7 most probably due to the increase of non-radiative process.

We then consider how each fluorescence component will be influenced by microenvironmental effects of IPCT complex. The $\left(\mathrm{D}^{-} \mathrm{A}^{+}\right)_{s}$ complex which showed the fluorescence band predominantly at $402 \mathrm{~nm}$ below $\mathrm{T}_{\mathrm{g}}$ and the fastest decay most probably have a structure that a donor and an acceptor are rigidly held in a face-to-face sandwich manner. The second local minimum in $\left(\mathrm{D}^{-} \mathrm{A}^{+}\right)_{s} *$ with the fluorescence band at $432 \mathrm{~nm}$ will correspond to a configuration with larger mutual distance and/or orientation between a donor and an acceptor. The $\left(\mathrm{D}^{-} \mathrm{A}^{+}\right) l$ complex which showed the fluorescence peak at $500 \mathrm{~nm}$ and longer lifetime would have a structure that a donor and an acceptor are partially overlapped.

\section{Conclusion}

The time-resolved fluorescence spectra of ion-pair charge-transfer complexes of $\mathrm{PV}^{2+}\left(\mathrm{TFPB}^{-}\right)_{2}$ depended on temperature, which was reversible during cooling and heating processes between $300^{\circ} \mathrm{K}$ and $10^{\circ} \mathrm{K}$. The fluorescence band at $400 \mathrm{~nm}$ shifted to $432 \mathrm{~nm}$ with 
temperature above $\mathrm{Tg}$. In addition to them the fluorescence spectra with a peak around $500 \mathrm{~nm}$ a slower decay were observed.

The observed IPCT fluorescence behavior was explained by considering two kinds of IPCT complexes which correspond to the different configuration of the donor and the acceptor. The potential surface of the excited state for one of them was assumed to have two local minima and contributed to the fluorescence spectral shift with temperatures, whereas no temperature dependence was observed for the fluorescence excitation spectra.

Acknowledgements The authors would thank Fuji Photo Film for the time-resolved fluorescence spectrum and the fluorescence lifetime measurements. The authors acknowledge Mr. Kawai of Shizuoka Universty for the DSC measurement.

\section{References}

1. H. Duirr and H. Bouas-Laurent, Photochromism Molecules and Systems (Elsevier, Amsterdam, 1990), p.1.

2. T. Nagamura and K. Sakai, J. Chem. Soc. Faraday Trans. 1, 84, 3529 (1988).

3. T. Nagamura and S. Muta, J. Photopolym. Sci. Technol., 4, 55 (1991).

4. T. Nagamura and K. Sakai, J. Chem. Soc., Chem. Commun., 810 (1986).

5. T. Nagamura and K. Sakai, Ber. Bunsenges. Phys. Chem., 93,1432 (1989).

6. T. Nagamura, K. Sakai and T. Ogawa, J. Chem. Soc., Chem. Commun., 1035 (1988).

7. T. Nagamura, K. Sakai and T. Ogawa,Proc. MRS Int. Meeting Adv. Mater., 12, 231 (1989).

8. T. Nagamura and K. Sakai, Thin Solid Films, 179, 375 (1989).

9. T. Nagamura, Y. Isoda, K. Sakai and T. Ogawa, J. Chem. Soc., Chem. Commun., 703 (1990).

10. T. Nagamura, Y. Isoda, K. Sakai and T. Ogawa, Thin Solid Films, 210/211, 617 (1992).

11. T. Nagamura, Mol. Cryst. Liq. Cryst., 224, 75 (1993).

12. T. Nagamura and Y. Isoda, J. Chem. Soc., Chem. Commun., 72 (1991).

13. T. Nagamura, Y. Isoda and K. Sakai, Ploym. Int., 27, 125 (1992).

14. T. Nagamura, S. Muta and K. Sakai, J. Photopolym, Sci. Technol., 5, 561 (1992).

15. T. Nagamura, H. Sakaguchi, T. Ito and S. Muta, Mol. Cryst. Liq. Cryst., 247, 39 (1994).

16. T. Nagamura and K. Sakai, Chem. Phys. Lett.,141, 553 (1987).

17. T. Nagamura and K. Sakai, Ber. Bunsenges. Phys. Chem., 92 , 707 (1988).

18. H. Nishida, N. Takada, M. Yoshimura, T. Sonoda and H. Kobayashi, Bull. Chem. Soc. Jpn., 57,2600 (1984).

19. K. Sakai, S. Muta and T. Nagamura, J. Photochem. Photobiol, A: Chem., in press.

20. T. Nagamura, H. Sakaguchi and T. Ito, unpublished results. 